\title{
Nicotine: Pharmacology, Toxicity and Therapeutic use
}

Karl Fagerström

Fagerstrom Consulting AB, Framnäsvägen 8, 18531 Vaxholm, Sweden

\section{Introduction}

Nicotine is naturally found in the plants belonging to the Solanaceae family. Concentrations high enough to have a pharmacological effect are seen only in the tobacco subfamily, approximately $2 \%$ of dry weight and in Duboisia Hopwoodii that has been used by Australian aborigines (http://en.wikipedia.org/wiki/Duboisia_hopwoodii). It is also present in the range of 2-7 microgram per $\mathrm{kg}$ of various edible plants.

Nicotine in the vehicle of tobacco has been used by humans for thousands of years. (Wilbert, 1993). It has been used in many forms but often and more recently, at least in the Western world, almost only in smoked forms. Nicotine consumed with tobacco is probably the second most used drug in the world after caffeine from coffee and tea. Tobacco/nicotine is consumed regularly across all countries, cultures and almost all religions. Thirtyone percent of men and $6 \%$ of women are tobacco users globally 2012 (Ng et al., 2014). Particularly in the western part of the world, smokers have been under great pressure to stop for the last 40 years or so. The prevalence has been halved in many countries but still almost $20 \%$ of the adult population is using tobacco in the English speaking world. In the EU $32 \%$ of men and $24 \%$ of women were smokers 2012 (EU Barometer).

\section{Morbidity and Mortality from Smoking}

The impacts of smoking on global health status are daunting. Smoking is the single largest cause of avoidable premature death and is responsible for $18.5 \%$ of all deaths in economically developed countries and is rapidly achieving this status outside the developed world (Lopez et al., 2006). Currently smoking causes 5 million deaths/year globally and that by approximately 2025 this will increase to about 10 million deaths each year (Peto et al., 1996) unless a good substitute for cigarettes or much more effective regulation of smoking takes place.

Recently, US celebrated the 50 year's anniversary of the first Surgeon General's report 1964 on smoking and up to date estimates of the mortality during this period has been calculated to 20 million. Most were adults with a history of smoking, but nearly 2.5 million were nonsmokers who died from heart disease or lung cancer caused by exposure to second hand smoke. Another 100,000 were babies who died of sudden infant death syndrome or complications from prematurity, low birth weight, or other conditions caused by parental smoking (US Department of Health and Human Services, 2014). As a response to these grim facts WHO negotiated a worldwide treaty that was adopted in 2003 with the aim to reduce tobacco use.

All forms of tobacco are not equally harmful. The health risks of smokeless tobacco are considerably lower than those associated with combustible tobacco products (Fiore, Schroeder \& Baker, 2014). The major benefits of smokeless tobacco products over combustible products are the virtual absence of respiratory risks, and potentially lower cardiovascular risks which are due to the absence of the gaseous components in smoke. However, it is also clear that the risks among smokeless tobacco products vary. The Swedish product called snus has not been found to be reliably associated with any cancer or respiratory disorders. From the cardiovascular field an increased risk of a more serious outcome of MIs and strokes have been seen in some studies (Lee, 2007). In contrast, in pregnancy snus as cigarettes has been seen to increase risk of adverse outcomes (Wikström, Cnattingius, \& Stephansson, 2010a; 2010b).

\section{Pharmacology}

Nicotine in its base form is an odour and colourless liquid. It is metabolized hepatically with a half-life of app 2 hours and the protein binding is $<5 \%$. Bioavailability is route dependent with the highest app $90 \%$ when inhaled (e.g. cigarettes) and approximately $60 \%$ when used orally (e.g. smokeless tobacco) (Jacob, Benowitz \& Shulgin, 1988; Lunell \& Lunell, 2005).

The fundamental pharmacological effect of nicotine is its action on the nicotinic acetylcholinergic receptors 
(nAChRs). Although nicotine directly activates only the nicotinic and not the muscarinic receptors, the end result is often a complex pattern of indirect effects on other transmitter systems such as the dopamine glutamate and adrenergic systems. Activation of central nAChRs may result in beneficial effects of nicotine such as cognitive enhancement and increased control over arousal and negative emotions (Sherwood, 1993). An exception to the primary role of brain $\mathrm{nAChR}$ beneficial effects may be the metabolic and lipolytic processes involved in weight control, which seem to be more peripherally mediated (Perkins, 1993). Like acetylcholine, nicotine stimulates the nAChRs, but when the nicotine molecule is bound to the receptor, it seems to keep the receptors depolarized for longer than what happens with acetylcholine. Nicotine therefore has a dual effect: stimulation of the receptor - agonist function, followed by a receptor blockade antagonist function. These effects interfere with normal functioning in nicotine intolerant individuals, therefore the CNS needs to adapt to the disrupting effects of nicotine. Blocking appears to be a more significant effect than stimulation since the brain adjusts and overcomes blocking, rather than stimulation, by upregulating the number of nicotine receptors (Benwell Balfour \& Birrell, 1995). Neuroadaptation can be seen as the organism's mean of defence against the toxic effects of nicotine.

The upregulation is dependent on the mode of administration. Chronic infusion of nicotine has been associated with greater upregulation than injections (Ulrich, Hargreaves, \& Flores, 1997), and it is thought that those who smoke more often and with shorter intervals are administering nicotine in a way that is more conducive to receptor upregulation, compared with those smoking just a few cigarettes per day with long intervals between. If nicotine administration is finally stopped, the system has too many nAChRs to function properly, which often results in withdrawal symptoms. The objective for the cholinergic nervous system when nicotine administration stops is to readapt to the nicotine-free state. This readaptation differ for individuals but some data for the important $\mathrm{nAChR}$ subtype beta 2 subunit suggest that it normalizes to nonsmoker levels by 6-12 weeks of abstinence from tobacco smoking (Cosgrove et al., 2009).

\section{Dependence to Tobacco. Is it All about Nicotine?}

Nicotine plays a central role in tobacco use. It is a necessary condition for regular tobacco use but is it sufficient? Cigarette smoking seems to create a dependence in users as fast if not faster than other drugs (DiFranza \& Ursprung, 2010) and develops to a level or degree of dependence equal to the so-called hard drugs (US Department of Health and Human Services, 1988).

The notion that it is solely an addiction to nicotine is difficult to reconcile with the observations below: a) Animals do not self-administer nicotine as readily as they do "hard drugs" like amphetamine, cocaine, and heroin (Villegier, Blanc, Glowinski, \& Tassin, 2003).

b) Nicotine is also a relatively weak reinforcer in human laboratory studies (Hughes, Rose \& Callas, 2000; Perkins, Gerlach, Broge, Fonte, \& Wilson, 2001).

c) Abstinent smokers seem to prefer a much reduced nicotine content cigarette over nicotine-containing products like gum and the reduced nicotine cigarette reduces craving (Barrett, 2010; Buchhalter Acosta, Evans, Breland \& Eissenberg, 2005) and alters brain nicotinic acetylcholine receptor occupancy (Brody et al., 2009). The so-called "scratch" in the throat may be of importance for these effects.

d) Although nicotine replacement (NR) treatment is an effective aid for quitting smoking, its efficacy is moderate (Fiore et al., 2008) even if doses that replace most or all nicotine from the cigarettes are used (Dale et al., 1995).

e) There is no evidence for the abuse of pure nicotine.

f) There seem to be a continuum of dependence so that cigarette smoking is most difficult to give up. Smokeless tobacco is easier to end and the easiest is to stop with long-term use of pure nicotine products, usually nicotine gum (Fagerstrom \& Eissenberg, 2012).

Tobacco seems to have additional effects beyond nicotine. Tobacco smoke is made up of thousands of chemicals. The interesting question is whether any of these also contributes to the reinforcing properties of tobacco smoke. It has been known for some time that cigarette smoke inhibits monoamine oxidase (MAO), the enzyme that catalyses the metabolism of monoamine neurotransmitters, such as dopamine, thus potentiating their effects in the brain of smokers and thereby contributing significantly to reward and dependence (Fowler et al., 2003). Nicotine is not directly responsible for this effect (Fowler et al., 1999). Acetaldehyde, an established constituent of tobacco smoke, is a potent inhibitor of MAO (both the A and the B subtypes), and it has been suggested that this compound causes the MAO inhibition. In experimental rats, nicotine self-administration is enhanced when the animals are also treated with acetaldehyde. Other studies suggest that the condensation products of acetaldehyde, salsolinol, and the harmans are more likely candidates as the inhibitors MAO. Salsolinol (Rodd et al., 2003) and harmans (Baum, Hill, \& Rommelspacher, 1996) nornicotine, anatabine and anabasine (nicotine alkaloids) are also themselves directly rewarding in rats (Clemens, Cailille, Stinus \& Cador, 2009). Interestingly rats also self-administer infusions of tobacco particulate matter better than nicotine (Brennan et al., 2013).

Up until about 30 years ago cigarette smoking was regarded as simply a strong habit, and many smokers still hold that view. Is it possible that in pursuing the search for the mechanisms underpinning the dependence upon 
nicotine and tobacco, researchers may have overlooked the other aspects of the smoking habit that may also be important, e.g. the habit and conditioning associated with smoking, the role of the object - that is, the cigarette itself and the psychosocial aspects of smoking. A fair summary of the role of nicotine seems to be that it is a necessary component but not sufficient to develop a strong dependence.

\section{The Safety and Toxicity of Nicotine}

Nicotine is a stimulant in low doses and a depressant of nervous activity in very high doses. In such doses approximately $500 \mathrm{mg}$ it can cause death by generalized blockade of e.g. respiration (Meyer, 2013). The actual lethal dose is dependent on many factors, e.g. if the organism is tolerant, the speed of delivery and the route of administration. There are examples, although rare, of lethal intoxications - suicides mostly - by e.g. transdermal patches or one ingestion of e-cigarette liquid (Kloosterman, 2013).

While there is a wealth of literature on the harmful effects of smoking - it kills half of its long-term users - much less is known about nicotine itself isolated from tobacco although it is generally understood that it is not the nicotine itself that is so harmful, but the method of delivery, i.e. the burning of tobacco (ASH, 2007). Most of the long-term effects of nicotine are commonly inferred from the many epidemiological studies made on snus since there is little safety data from long-term use of NR products. Snus users consume as much nicotine as smokers and more than NR product users. Since snus also contains other potentially harmful substances such as nitrosamines and metals it is considered being a conservative estimate of the nicotine effects.

The areas of main concern regarding the safety of nicotine have been the ones where tobacco smoking has been found to be most harmful, i.e. cancer, pregnancy, cardiovascular and respiratory diseases.

\section{Cancer}

There is some biological basis for proposing that nicotine may promote cancer based on experimental studies that have limitations in replicating human exposure and on mechanistic studies, but human evidence is lacking (Chen, Ho, Guo \& Wang, 2008b; Lee \& Cooke, 2012).

There are 69 identified carcinogens in tobacco smoke, but nicotine is not among them (International Agency for Research on Cancer, 2004; 2007). If nicotine alone were to cause cancer, one would expect that long-term exposure to nicotine from snus would cause cancer. However, studies have seen no increased risk of cancer in either the oral cavity or the throat after snus use (Lewin et al., 1998; Schildt, Eriksson, Hardell, \& Magnuson, 1998). Furthermore, a recent meta-analysis by Lee found no association between snus and cancer of the oropharynx, oesophagus, stomach, pancreas, lung or other sites (Lee, 2011). Two studies have reported suggestive evidence of an association between the use of snus and pancreatic cancer, oesophageal squamous cell carcinoma and noncardia stomach cancer (Luo et al., 2007; Zendehdel et al., 2008).

The only large, long-term study published to date on a NR product - gum - found no association between NR products and the development of cancers among former smokers (Murray, Connett \& Zapawa, 2009). In this Lung Health Study, a 5-year prospective study of 3,320 patients, it was found that use of NR was not a significant predictor of lung cancer, gastrointestinal cancers or all cancers, whereas continued smoking was a significant predictor of lung cancer. Nevertheless, some people continue to believe that nicotine causes cancer (Cummings et al., 2004) including a significant minority of healthcare professionals working in stop smoking services (Beard, McDermott, McEwen \& West, 2012).

\section{Cardiovascular Disease}

Although it is recognized that medicinal nicotine causes temporary changes to the cardiovascular system epidemiological studies have not found the use of NR to be linked to the development of cardiovascular disease (Benowitz, Hansson \& Jacob, 2002; Hubbard et al., 2005) and studies have shown that NR need not be contraindicated for smokers with heart disease (Greenland, Satterfield, \& Lanes, 1998; Kimmel et al., 2001). In a study that evaluated the safety of NRT in 663 patients after acute coronary syndrome, NR use for 1 year was not associated with an increased risk of cardiovascular events (Joseph et al., 1996).

Several studies have been conducted on long-term users of snus to evaluate the risk of cardiovascular heart disease, myocardial infarction or stroke. A recent metaanalysis of eight prospective observational studies concluded that snus use was not associated with acute myocardial infarction (Hansson et al., 2012). Although it was suggested that snus use might slightly increase the risk for a more severe outcome in patients with stroke and a nonfatal myocardial infarction. (Hergens et al., 2007).

\section{Pregnancy}

Pregnant women who use snus are at higher risk of having babies of lower birth weight, elevated risks for premature delivery, still birth and possibly pre-eclampsia (Baba, Wikström, Stephansson, \& Cnattingius, 2013; Wikström et al., 2010a). From animal work it seems likely that nicotine may also have adverse neurobehavioral consequences (Pauly \& Slotkin, 2008).

\section{Therapeutic Effects of Nicotine}

Tobacco/nicotine when it was introduced in Europe was said to have medicinal applications. Since a large part of the world's population is using tobacco, one would think that it brings some benefit to the users. Apart from what the smokers tell us, that tobacco calms, reduces stress, helps concentration and regulates appetite and increases energy turnover, it has also been found to enhance the 
reinforcing value of other reinforcers (Chaudhri et al., 2006). Further tobacco/nicotine has been found to be negatively associated with a number of disorders; Parkinson's and Alzheimer's diseases, allergic alveolitis, nausea and vomiting of pregnancy, pre-eclampsia, fibroids, carcinoma of body of uterus, ulcerative colitis, pyoderma gangrenosum, aphthous stomatitis and ulceration, pemphigus, herpes simplex and acne (Wolf, Orion, Matz, Maitra, \& Rowland-Payne, 2004). For nicotine the body of research is much thinner. Nicotine's main and only therapeutic area today is for treatment of tobacco dependence. A good number of NR products have been developed and licensed as effective treatments for tobacco dependence. However, nicotine isolated from tobacco has been tried as a treatment for many conditions and disorders and some positive effects have been observed in preliminary studies in the following conditions: ulcerative colitis (Sandborn, 1999), major depression (McClernon, Hiott, Westman, Rosse, \& Levin, 2006), Tourettes's syndrome (Silver et al., 2001), neuroleptic-induced akathisia (Anfang \& Pope, 1997), cognition in schizophrenia (Barr et al., 2008), attention deficit hyperactivity disorder (Gehricke Hong, Whalen, Steinhoff \& Wigal, 2009), Parkinsons disease (Thiriez et al., 2011) and mild cognitive impairment (Newhouse et al., 2012). The best evidence is available for Parkinson's disease (Fagerström \& Pomerleau, 1994; Thiriez et al., 2011) and ulcerative colitis (Green et al., 1997; Sandborn, 1999). For Parkinson's disease a study found that smokeless tobacco users had a protective effect with an age adjusted risk of only $0.22(0.07-0.67)$ to die from Parkinson's disease compared with never tobacco users (O’Reilly et al., 2005). While cigarette smoking is a risk factor for multiple sclerosis, the use of snus had a protective effect with evidence of an inverse doseresponse correlation between cumulative dose of snus and the risk of developing MS (Hedstrom, Hillert, Olsson \& Alfredsson, 2013).

Many of the medicines for these conditions (e.g. Alzheimers disease) have marginal efficacy and it is quite likely that nicotine would have no better effect alone. However, maybe combining nicotine with the other medications would increase the efficacy of the treatment.

\section{Nicotine in the Society: Beneficial or Detrimental Effects}

Nicotine has a dependence potential although less than when it comes with tobacco. Exactly how dependence is provoking nicotine without tobacco is not clear but it depends on how much behaviour and sensory stimulation will be associated with the nicotine product. The dependence potential is shared by the other "cultural drugs" caffeine and alcohol. It can be assumed that the dependence potential for pure nicotine will be in the same range as that to caffeine. The dependence potential to alcohol is of a different kind with fewer users becoming dependent but for those who do develop dependence the consequences, both medical and social, are more severe.
While nicotine, as coffee and alcohol, contributes risks to pregnancy, it has, as far as is known, few other direct harms. This is in sharp contrast to alcohol which is a risk factor for many serious disorders and behaviours although moderate amounts can also be protective for some disorders. How well the established neuroprotective effects (Sieber, 2012) of nicotine will turn into disease protection is not known. Unfortunately there is a certain amount of reluctance among researchers to study the potential positive effects of nicotine because the substance is linked to tobacco and mostly manufactured and marketed by the hated tobacco industry. The electronic cigarettes with their very fast uptake in many countries may change the nicotine landscape. The tobacco industry may not become the whole owner of this commodity which opens up for more engagement from scientists. Further, since electronic cigarettes in all likelihood are significantly less harmful than traditional cigarettes and are more liked by smokers than NR products, the electronic cigarettes may be a game changer that can threaten the monopoly that cigarettes have had for people engaging in tobacco/nicotine.

\section{Acknowledgements}

The author is a consultant to many companies with an interest in nicotine such as pharmaceutical companies marketing NRT and electronic cigarette manufacturers.

\section{Financial Support}

No financial support has been used for this paper.

\section{Conflict of interest}

None.

\section{Ethical Standards}

None.

This Editorial is published alongside a video interview between the author and the Editor-in-Chief of Journal of Smoking Cessation. The interview can be viewed at: http://journals.cambridge.org/jsc/video/fagerstrom

\section{References}

Anfang, M. K., \& Pope, H. Jr. (1997). Treatment of neuroleptically-induced akathisia with nicotine patches. Psychopharmacology, 134, 153-156.

ASH (Action on Smoking, Health) (2007). Nicotine replacement therapy guidelines for healthcare professionals on using nicotine replacement therapy for smokers not yet ready to stop smoking. (17 pp.). ASH (Action on Smoking, Health) (2012). E-cigarette use in Great Britain: 2010 and 2012.

Baba, S., Wikström, A. K., Stephansson, O., \& Cnattingius, S. (2013). Changes in snuff and smoking habits in Swedish pregnant women and risk for small for gestational age births. BJOG: An International Journal of Obstetrics \& Gynaecology, 120(4), 456-462. doi: 10.1111/1471-0528.12067. Epub 2012 Nov 27. 
Barr, R. S., Culhane, M. A., Jubelt, L. E., Mufti, R. S., Dyer, M. A., Weiss, A. P. et al. (2008). The effects of transdermal nicotine on cognition in nonsmokers with schizophrenia and nonpsychiatric controls. Neuropsychopharmacology, 33(3), 480-490. Epub 2007 Apr 18.

Barrett, S. P. (2010). The effects of nicotine, denicotinized tobacco, and nicotine-containing tobacco on cigarette craving, withdrawal, and self-administration in male and female smokers. Behavioural Pharmacology, 21, 144-152. doi:10.1097/FBP.0b013e328337be68.

Baum, S. S., Hill, R., \& Rommelspacher, H. (1996). Harmaninduced changes of extracellular concentrations of neurotransmitters in the nucleus accumbens of rats. European Journal of Pharmacology, 314, 75-82. doi:10.1016/S00142999(96)00543-2.

Beard, E., McDermott, M., McEwen, A., \& West, R. (2012). Beliefs of stop smoking practitioners in United Kingdom on the use of nicotine replacement therapy for smoking reduction. Nicotine \& Tobacco Research, 14(1469-994X (Electronic)), 639-647. Available at: http://www.ncbi.nlm.nih.gov/pubmed/22180579. Accessed October 10, 2012.

Benowitz, N. L., Hansson, A., \& Jacob, P. I. (2002). Cardiovascular effects of nasal and transdermal nicotine and cigarette smoking. Hypertension, 39(1524-4563 (Electronic)), 11071112 .

Benwell, M. E. M., Balfour, D., \& Birrell, C. E. (1995). Desensitization of nicotine-induced mesolimbic dopamine response during constant infusion with nicotine. British Journal of Pharmacology, 114, 454-460.

Brennan, K. A., Crowther, A., Putt, F., Roper, V., Waterhouse, U., \& Truman, P. (2013). Tobacco particulate matter selfadministration in rats: Differential effects of tobacco type. Add Biology, doi:10.1111/adb.12099.

Brody, A. L., Mandelkern, M. A., Costello, M. R., Abrams, A. L., Scheibal, D., Farahi, J. et al. (2009). Brain nicotinic acetylcholine receptor occupancy effect of smoking a denicotinized cigarette. International Journal of Neuropsychopharmacology, 12, 305-316. doi:10.1017/S146114570800922X.

Buchhalter, A. R., Acosta, M. C., Evans, S. E., Breland, B., \& Eissenberg, T. (2005). Tobacco abstinence symptom suppression: The role played by the smoking-related stimuli that are delivered by denicotinized cigarettes. Addiction, 100, 550-559. doi:10.1111/j.1360-0443.2005.01030.x.

Chaudhri, N., Caggiula, A. R., Donny, E. C., Palmatier, M. I., Liu, X., \& Sved, A. F. (2006). Complex interactions between nicotine and nonpharmacological stimuli reveal multiple roles for nicotine in reinforcement. Psychopharmacology (Berl), Mar, 184(3-4), 353-366. Epub 2005 Oct 21. Review.

Chen, R .J., Ho, Y. S., Guo, H. R., \& Wang, Y. J. (2008b). Rapid activation of Stat 3 and ERK1/2 by nicotine modulates cell proliferation in human bladder cancer cells. Toxicological Sciences, 104(2), 283-293.

Clemens, K. J., Cailille, S., Stinus, L., \& Cador, M. (2009). The addition of five minor tobacco alkaloids increases nicotineinduced hyperactivity, sensitization and intravenous selfadministration in rats. International Journal of Psychopharmacology, 12, 1355-1366. doi:10.1017/S1461145709000273.
Cosgrove, K. P., Batis, J., Bois, F., Maciejewski, P. K., Esterlis, I., Kloczynski, T. et al. (2009). 2-Nicotinic acetylcholine receptor availability during acute and prolonged abstinence from tobacco smoking. Archives of General Psychiatry, 66(6), 666-676.

Cummings, K. M., Hyland, A., Giovino, G. A., Hastrup, J. L., Bauer, J. E., \& Bansal, M.A. (2004). Are smokers adequately informed about the health risks of smoking and medicinal nicotine? Nicotine \& Tobacco Research, 6 Suppl 3(December), S333-S340. Available at: http://www.ncbi.nlm.nih.gov/pubmed/15799596.

Dale, L. C., Hurt, R. D., Offord, K. P., Lawson, G. M., Croghan, I. T., \& Schroeder, D. R. (1995). High-dose nicotine patch therapy. Percentage of replacement and smoking cessation. Journal of the American Medical Association, 274, 1353-1358. doi:10.1001/jama.1995.0353017003.

DiFranza, J., \& Ursprung, W. W. (2010). A systematic review of the international classification of diseases criteria for the diagnosis of tobacco dependence. Addictive Behaviors, 35, 805-810. doi:10.1016/j.addbeh.2010.04.002.

EU Barometer 385. Available at: http://ec.europa.eu/ public_opinion/index_en.htm.

Fagerstrom, K., \& Eissenberg, T. (2012). Dependence on tobacco and nicotine products: A case for product-specific assessment. Nicotine \& Tobacco Research, 14, 1382-1390. doi: $10.1093 /$ ntr/nts007.

Fagerström, K. O., \& Pomerleau, O. (1994). Nicotine may relieve symptoms of parkinsons disease. Psychopharmacology, 116, 117-119.

Fiore, M.C., Jaen, C.R., Baker, T.B., Bailey, W.C., Benowitz, N., Curry, S.J. et al. (2008). Treating tobacco use and dependence: 2008 update. Rockville, MD: U.S. Department of Health and Human Services. Retrieved from http://www.ahrq.gov/path/tobacco.htm\#Clinic.

Fiore, M. C., Schroeder, S. A., \& Baker, T. B. (2014). Smoke, the chief killer - strategies for targeting combustible Tobacco use. New England Journal of Medicine, 370, 297-299. January 23, 2014, doi: 10.1056/NEJMp1314942.

Fowler, J. S., Logan, J., Wang, G. J., Volkow, N. D., Telang, F., Zhu, W. et al. (2003). Low monoamine oxidase B in peripheral organs in smokers. Proceedings of the National Academy of Sciences of the United States of America, 30, 11600-11605. doi:10.1073/pnas.1833106100.

Fowler, J.S., Wang, G. J., Volkow, N. D., Franceschi, D., Logan, J., Pappas, N. et al. (1999). Smoking a single cigarette does not produce a measurable reduction in brain MAO B in non-smokers. Nicotine \& Tobacco Research, 1, 325-329. doi:10.1080/14622299050011451.

Gehricke, J. G., Hong, N., Whalen, C. K., Steinhoff, K., \& Wigal, T. L. (2009). Effects of transdermal nicotine on symptoms, moods, and cardiovascular activity in the everyday lives of smokers and nonsmokers with attentiondeficit/hyperactivity disorder. Psychology of Addictive Behaviors, Dec, 23(4), 644-655. doi: 10.1037/a0017441.

Green, J.T., Thomas, G.A., Rhodes, J., Williams, G.T., Evans, B.K., Russell, M.A. et al. (1997). Nicotine enemas for active ulcerative colitis-a pilot study. Alimentary Pharmacology \& Therapeutics, Oct, 11(5), 859-863. 
Greenland, S., Satterfield, M. H., \& Lanes, S. F. (1998). A meta-analysis to assess the incidence of adverse effects associated with the transdermal nicotine patch. Drug Safety: An International Journal of Medical Toxicology and Drug Experience, 18(4), 297-308. Available at: http://www.ncbi.nlm.nih.gov/pubmed/9565740. Accessed October 10, 2012.

Hansson, J., Galanti, M. R., Hergens, M.-P., Fredlund, P., Ahlbom, A., Alfredsson, L. et al. (2012). Use of snus and acute myocardial infarction: Pooled analysis of eight prospective observational studies. European Journal of Epidemiology, Oct, 27(10), 771-779. Available at: http://www.ncbi.nlm.nih.gov/ pubmed/22722951. Accessed October 9, 2012.

Hedstrom, A. K., Hillert, J., Olsson, T., \& Alfredsson, T. (2013). Nicotine might have a neuroprotective effect in the etiology of multiple sclerosis. Multiple Sclerosis, Jul, 19(8), 1009-1013. doi: 10.1177/1352458512471879. Epub 2013 Jan 14.

Hergens, M. P., Alfredsson, L., Bolinder, G., Lambe, M., Pershagen, G., \& Ye, W. (2007). Long-term use of Swedish moist snuff and the risk of myocardial infarction amongst men. Journal of Internal Medicine, 262(0954-6820 (Print)), 351-359.

Hubbard, R., Lewis, S., Smith, C., Godfrey, C., Smeeth, L., Farrington, P. et al. (2005). Use of nicotine replacement therapy and the risk of acute myocardial infarction, stroke, and death. Tobacco Control, 14(6), 416-421. Available at: http://www.pubmedcentral.nih.gov/articlerender.fcgi? artid $=1748112 \&$ tool $=$ pmcentrez\&rendertype $=$ abstract . Accessed October 9, 2012.

Hughes, J. R., Rose, G. L., \& Callas, P .W. (2000). Nicotine is more reinforcing in smokers with a past history of alcoholism than in smokers without this history. Alcoholism: Clinical and Experimental Research, 24, 1633-1638. doi:10.1111/j.15300277.2000.tb01964.x.

International Agency for Research on Cancer (2004). Tobacco smoke and involuntary smoking. IACR Monograph, Volume 83. Lyon; 2004, 1452 pp. Available at: http://monographs.iarc.fr/ENG/Monographs/vol83/ index.php.

International Agency for Research on Cancer (2007). Some tobacco-specific N-nitrosamines. IACR Monograph, Volume $89,583$.

Jacob, P. 3rd, Benowitz, N. L., \& Shulgin, A. T. (1988). Recent studies of nicotine metabolism in humans. Pharmacology Biochemistry Behavior, 30(1), 249-253.

Joseph, A., Norman, S., Ferry, L., Prochazka, A. V., Westman, E. C., Steele, B. G. et al. (1996). The safety of transdermal nicotine as an aid to smoking cessation in patients with cardiac disease. The New England Journal of Medicine, 335, 1792-1798.

Kimmel, S. E., Berlin, J. A., Miles, C., Jaskowiak, J., Carson, J. L., \& Strom, B. L. (2001). Risk of acute first myocardial infarction and use of nicotine patches in a general population. Journal of the American College of Cardiology, 37(5), 1297-1302. Available at: http://www.ncbi.nlm.nih.gov/pubmed/11300438.

Kloosterman, K. (2013). Electronic cigarette kills toddler in Israel. Green Prophet, 29 May. 2013. Avail- able at: http://www.greenprophet.com/2013/05/electroniccigarette-kills-toddler-in-israel/ (accessed 4 April 2014) (Archived at http://www.webcitation.org/6QnAb1ls9 on 3 July 2014).

Lee, J., \& Cooke, J. P. (2012). Nicotine and pathological angiogenesis. Life Sciences, 91(21-22), 1058-1064.

Lee, P. N. (2007). Circulatory disease and smokeless tobacco in Western populations: A review of the evidence. International Journal of Epidemiology, 36(4), 789-804. Available at: http://www.ncbi.nlm.nih.gov/pubmed/17591642. Accessed October 9, 2012.

Lee, P. N. (2011). Summary of the epidemiological evidence relating snus to health. Regulatory Toxicology and Pharmacology, 59(1096-0295 (Electronic)), 197-214.

Lewin, F., Norell, S. E., Johansson, H. et al. (1998). Smoking tobacco, oral snuff, and alcohol in the etiology of squamous cell carcinoma of the head and neck: A population-based casereferent study in Sweden. Cancer, 82(7), 1367-1375. Available at: http://www.ncbi.nlm.nih.gov/pubmed/9529030. Accessed February 11, 2013.

Lopez, A. D., Christopher, J. L., Murray, M. D., Gakidou, E., Mathers, C. D., Ezzati, M. et al. (2006). Global burden of disease and risk factors. Washington DC: The World Bank Group and New York: Oxford University Press, 2006. www.dcp2.org/pubs/GBD (accessed 7 August 2007).

Lunell, E., \& Lunell, M. (2005). Steady-state nicotine plasma levels following use of four different types of Swedish snus compared with 2-mg Nicorette chewing gum: A crossover study. Nicotine \& Tobacco Research, , 7(3), 397403.

Luo, J., Ye, W., Zendehdel, K., Adami, J., Adami, H. O., Boffetta, P. et al. (2007). Oral use of Swedish moist snuff (snus) and risk for cancer of the mouth, lung, and pancreas in male construction workers: A retrospective cohort study. Lancet, 369(1474-547X (Electronic)), 2015-2020.

McClernon, F. J., Hiott, F. B., Westman, E. C., Rosse, J. E., \& Levin, E. D. (2006). Transdermal nicotine attenuates depression symptoms in non-smokers: A double blind, placebo controlled trial. Psychopharmacology, 189, 125-133.

Meyer, B. (2013). How much nicotine kills a human? Tracing back the generally accepted lethal dose to dubious selfexperiments in the nineteenth century. Archives of Toxicology, $88,5-7.10 .1007 / \mathrm{s} 00204-013-1127-0$.

Murray, R. P., Connett, J. E., \& Zapawa, L. M. (2009). Does nicotine replacement therapy cause cancer? Evidence from the Lung Health Study. Nicotine \& Tobacco Research: Official journal of the Society for Research on Nicotine and Tobacco, 11(9), 1076-1082. Available at: http://www.pubmedcentral.nih.gov/articlerender.fcgi? artid $=2725009 \&$ tool $=$ pmcentrez\&rendertype $=$ abstract. Accessed October 9, 2012.

Newhouse, P., Kellar, K., Aisen, P., White, H., Wesnes, K., Coderre, E. et al. (2012). Nicotine treatment of mild cognitive impairment: A 6-month double-blind pilot clinical trial. Neurology, Jan 10, 78(2), 91-101. doi: 10.1212/WNL.0b013e31823efcbb.

Ng, M., Freeman, M. K., Fleming, T. D., Robinson, M., DwyerLindgren, L., Thomson, B. et al. (2014). Smoking prevalence 
and cigarette consumption in 187 countries, 1980-2012. Journal of American Medical Association, 311(2), 183-192. doi:10.1001/jama.2013.284692.

O’Reilly, E. J., McCullough, M. L., Chao, A., Henley, S. J., Calle, E. E., Thun, M. J. et al. (2005). Smokeless tobacco use and the risk of Parkinson's disease mortality. Movement Disorders, 20(10), 1383-1384.

Pauly, J. R., \& Slotkin, T. A. (2008). Maternal tobacco smoking, nicotine replacement and neurobehavioural development. Acta Paediatrica, 97(10), 1331-1337. doi: 10.1111/j.16512227.2008.00852.x. Epub 2008 Jun 12.

Perkins, K. A. (1993). Weight gain following smoking cessation. Journal of Consulting and Clinical Psychology, 61, 768-777.

Perkins, K. A., Gerlach, D., Broge, M., Fonte, C., \& Wilson, A. (2001). Reinforcing effects of nicotine as a function of smoking status. Experimental and Clinical Pharmacology, 9, 243250. doi:10.1037/1064-1297.9.3.243.

Peto, R., Lopez, A. D., Boreham, J., Thun, M., Heath, C. Jr., \& Doll, R. (1996). Mortality from smoking worldwide. British Medical Bulletin, 52(1), 12-21.

Rodd, Z. A., Bell, R. L., Zhang, Y., Goldstein, A., Zaffaroni, A., McBride, W. J. et al. (2003). Salsolinol produces reinforcing effects in the nucleus accumbens shell of alcohol-preferring (P)rats. Alcoholism Clinical and Experimental Research, 27, 440-449. doi:10.1097/01.ALC.0000056612.89957.B4.

Sandborn, W. J. (1999). Nicotine therapy for ulcerative colitis: A review of rationale, mechanisms, pharmacology, and clinical results. The American Journal of Gastroenterology, 94(5), 1161-1171. Review.

Schildt, E. B., Eriksson, M., Hardell, L., \& Magnuson, A. (1998). Oral snuff, smoking habits and alcohol consumption in relation to oral cancer in a Swedish casecontrol study. International Journal of Cancer. Journal International $d u$ Cancer, 77(3), 341-346. Available at: http://www.ncbi.nlm.nih.gov/pubmed/9663593. Accessed February 11, 2013.

Sherwood, N. (1993). Effects of nicotine on human psychomotor performance. Human Psychopharmacology, 8, 155-184.

Sieber, M. (2012). Neuroprotective properties of nicotine. Current Medicinal Chemistry, 19(2), 292-297.

Silver, A. A., Shytle, R. D., Philipp, M. K., Wilkinson, B. J., McConville, B., \& Sanberg, P. R. (2001). Transdermal nicotine and haloperidol in Tourette's disorder: A double- blind placebo-controlled study. Journal of Clinical Psychiatry, 62(9), 707-714.

Thiriez, C., Villafane, G., Grapin, F., Fenelon, G., Remy, P., \& Cesaro, P. (2011). Can nicotine be used medicinally in Parkinson's disease? Expert Review of Clinical Pharmacology, Jul, 4(4), 429-436. doi: 10.1586/ecp.11.27. Review.

Ulrich, Y.M., Hargreaves, K.M., \& Flores, C.M. (1997). A comparison of multiple injections versus continuous infusion of nicotine for producing up-regulation of neuronal $[3 \mathrm{H}]$ epibatidine binding sites. Neuropharmacology, 36, 11191125.

US Department of Health and Human Services (1988). The health consequences of smoking. Nicotine addiction: A Report of the Surgeon-General. Rockville, MD: Author.

US Department of Health and Human Services (2014). The health consequences of smoking-50 years of progress. A Report of the Surgeon General. Atlanta, GA: U.S. Department of Health and Human Services, Centers for Disease Control and Prevention, National Center for Chronic Disease Prevention and Health Promotion, Office on Smoking and Health, 2014. Printed with corrections, January 2014.

Villegier, A. S., Blanc, G., Glowinski, J., \& Tassin, J. P. (2003). Transient behavioural sensitization to nicotine becomes long lasting with monoamine oxidase inhibitors. Pharmacology Biochemistry \& Behaviour, 76, 267-274. doi:10.1016/S00913057(03)00223-5.

Wikström, A. K., Cnattingius, S., \& Stephansson, O. (2010a). Maternal use of Swedish snuff (snus) and risk of stillbirth. Epidemiology, 21(1531-5487 (Electronic)), 772-778.

Wikström, A. K., Stephansson, O., \& Cnattingius, S. (2010b). Tobacco use during pregnancy and preeclampsia risk: Effects of cigarette smoking and snuff. Hypertension, 55(1524-4563 (Electronic)), 1254-1259.

Wilbert, J. (1993). Tobacco and Shamanism in South America ISBN 0-300-05790-3.

Wolf, R., Orion, E., Matz, H., Maitra, S., \& Rowland-Payne, C. (2004). Smoking can be good for you. Journal of Cosmetic Dermatology, 3(2), 107-111.

Zendehdel, K., Nyren, O., Luo, J., Dickman, P.W., Boffetta, P., Englund, A. et al. (2008). Risk of gastroesophageal cancer among smokers and users of Scandinavian moist snuff. International Journal of Cancer, 122(1097-0215 (Electronic)), 1095-1099. 